\title{
The zooecological remediation of technogen faulted soil in industrial region of Ukraine steppe zone
}

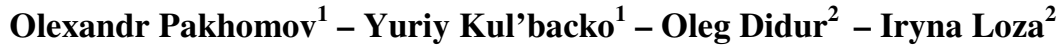 \\ Department of Zoology and Ecology, Biology, Ecology and Medicine Faculty, Dnepropetrovsk National University, Gagarina av., 72, \\ 49010 Dnepropetrovsk. Ukraine, e-mail: irinaloza@ hotmail.com, didur@ua.fm
}

Keywords: zooecological remediation, mining, sustainable agriculture, earthworms

\section{SUMMARY}

In Ukraine's Steppe zone the extraction of minerals is important. To eliminate the consequences of coal mining the agricultural recultivation of the disturbed soil is used. Thus toxic compounds for human beings and the majority of plants and soil biota representatives, which can be found mining rock, get into plants and invertebrates by trophy chains. When remediating soil, it is necessary to create tropic conditions in order to provide the life of soil biota. Earthworms (Lumbricidae) are the primary decomposers of the organic material. They are numerous in soil and facilitate the improvement of natural and artificially created soil. This paper studies the possible influence of different variants of substrates, which are used in re-cultivation, the leaf litter from leaves of different wood species, as well as different levels of humidity on the representatives of soil saprophages. Optimal variants of artificial mixed-soil providing the stable existence of animals have been shown, which are recommended for the implementation of rehabilitation measures.

\section{INTRODUCTION}

The rehabilitation of damaged soil is a particular practical and scientific interest, when creating steady artificial biogeocenos, the integral parts of which are soil invertebrates (Travleev et al., 1988; Zonn and Travleev, 1989; Grytsan, 2000; Kondratyuk, 1980). They are present in every site of the forest and agricultural re-cultivation. Soil invertebrates influence both the formation of vegetation and the stability of the whole artificial ecosystem.

The extraction of minerals is important for the intensive highly industrial regions of Ukraine. The Western Donbass is one of the most environmentally damaged regions of Ukraine. Covering $12500 \mathrm{~km}^{2}$ its coal seams containing reserves of about 25 billion tons, run under the Samara river Basin at depths of 0.2-0.7 km. Following mining, subsidence, equivalent to about $90 \%$ of the depth of the extracted layer, is common and large areas become flooded. By-products of the coal mining (toxic water-soluble salts, compounds of heavy metals) have negative impacts on the environment eliminating the soil from the nature management, which could be used by human being in the agricultural activity (Loza and Nazarenko, 2006).

The Steppe zone of Ukraine is situated in a continental-temperate climate area where moisture is the one of the main limiting factors. The soil covering in the Dnepropetrovsk region is heterogenous. It is caused by the difference in the climate, geomorphological features, and other natural factors. 277 subtypes of soil have been defined in the region (Soil of the Dnepropetrovsk region, 1966). Ordinary medium, low-humus chernozems (according to the classification of WRB, Chernozems Calcic) prevail. They occupy the most part of the territory and contain $4-5 \%$ of humus. Chernozems are highly productive soils on which the majority of agricultural crops (World Reference Base for Soil Resources, 1994; Polupan et al., 2005) is grown up. The area of agricultural recultivation in represented by the high-water bed of Samara river, where perspective variants of remediation of the damaged soil are used. The remediation involves the application of a 0.5-meter layer of loess loam and 0.50.7-meter of bulk chernozem on the true surface of mining spoil. This spoil is piled up by the mine spoil which is clay mass with impurities in coal and pyrite, with a large amount of toxic compounds for biota. The necessity of applying a 50-centimeter layer of loess loam is related to the protection from the vertical movement of toxical salts and heavy metals along the newly-made soil-and ecological profile (Kharytonov et al., 2005; Kharytonov and Zhylenko, 2006).

The main purpose of re-cultivation is the rehabilitation of the damaged territories, where the creation of highly productive plantation possessing high environmental converting properties is possible. For this purpose it is necessary to present all the ecosystem components - vegetation, soil, microbiocenosis, and animals. Soildwelling animals promote the improvement of the ecological properties of soil. Due to the various structural and functional characteristics they participate in the optimization of all ecosystems, including agrocenosis and increasing productivity. The participation of various taxons of animals in the improvement of soil structures, agrochemical characteristics, in the decomposition of plant residues and the transformation of organic substance is the necessary condition for the steady functioning of artificial ecosystems.

In the improvement of the structural and chemical composition of soil the leading part is played by soil saprophages among which a separate place is occupied by to earthworms (Vsevolodova-Perel, 1997; Gylarov, 1978). The high plasticity of this group of animals, the tropic activity and participation in the soil formation quite often have the decisive importance for soil preservation (Zrazhevsky, 1957; Ivantsiv, 2002). This is especially important when making artificial soil. During the previous researches of the authors it has been found that the 
presence of animal-saprophages in artificial mixed-soils promotes a more intensive evolution of carbon dioxide gas as one of the most important characteristics of soil bioactivity. The mining spoil thus has a negative influence on the parameters of soil aeration (Kul'bachko et al., 2007).

Among abiotic factors the temperature and humidity influence significantly the existence of soil invertebrates. They are the major ecological factors, in particular, the life of earthworms (Atlavinite, 1975).

When carrying out re-cultivation works, it is difficult to predict the state of the artificial ecosystem and the biota. In order to solve this problem, the laboratory researches are necessary, which would show what variants of artificial mixed-soils are optimal for the growth and development of plants and animals.

\section{MATERIALS AND METHODS}

The subjects of the research were earthworms (Lumbricidae). The purpose of the research was to determine the change in biomass of the representatives of decomposers of tree waste on different variants of artificial soil substrates.

To study the reaction of earthworms to environmental factors, the methods of the mathematical theory of planning and the modelling of complex systems were used. When designed the experiment, we used methods of the mathematical planning of the experiment (Nalymov, 1971; Tomashevsky, 2005).

When establishing trials, on the bottom of each culture container $\left(S=0.0201 \mathrm{~m}^{2}\right)$ the substrate served as the habitat for the subjects of the research. The mass of substrate in each experiment was the same $(0.7 \mathrm{~kg})$. The substrate was covered with foliage litter of the specified wood $(0.05 \mathrm{~kg}$ per culture container). Then ten animals were brought in each culture container. The starting weight of the animals was set.

In the laboratory where the pot trials were made, the temperature was maintained within the limits of 20-22 ${ }^{\circ} \mathrm{C}$, and precipitations of different amounts were simulated. Distilled water was used for watering in the experiments. The duration of the experiments was 30 days.

To solve the set problem, we have chosen the following conditions for the experiment.

Factor A (form of bulk substrate). Levels of factor are as follows:

$1-$ mine spoil with $\mathrm{pH}_{\mathrm{aquas}}=3.5$; solid $=0.60 \%$;

$2-$ chernozem with $\mathrm{pH}_{\mathrm{aquas}}=7.0 ;$ solid $\left.=0.05 \%\right)$;

3 - light loam with $\mathrm{pH}_{\text {aquas }}=7.5$; solid $=0.065 \%$ ).

Factor B (species belonging of litter). Levels of factor are as follows:

1 - eastern redcedar (Juniperus virginiana L.) with $\mathrm{pH}_{\mathrm{aquas}}(1: 10)=7.2$ );

2 - bosnian maple (Acer platanoides L.) with $\left.\mathrm{pH}_{\mathrm{aquas}}(1: 10)=5.9\right)$;

3 - false acacia (Robinia pseudoacacia L.) with $\left.\mathrm{pH}_{\text {aquas }}(1: 10)=6.95\right)$.

Factor C (humidification). Levels of factor are as follows:

1 - high (40 mm/month);

2 - moderate $(30 \mathrm{~mm} / \mathrm{month})$;

3 - low (20 mm/month).

1 .

As the plan of experiment Latin square $3 \times 3$ with double replication has been chosen, and it is given in Table

The design of experiment based on Latin square with three fixed levels

\begin{tabular}{|c|c|c|c|}
\hline \multirow{2}{*}{$\begin{array}{l}\text { Trial } \\
\text { No. }\end{array}$} & Substrate (A) & Litter (B) & $\begin{array}{l}\text { Humidification } \\
\text { (C) }\end{array}$ \\
\hline & \multicolumn{3}{|c|}{ Gradations of factor and the codes } \\
\hline 1 & (1) ${ }^{\text {Mine spoil }}$ & (1) Redcedar & High (1) \\
\hline 2 & $\begin{array}{l}\text { Chernozem } \\
\text { (2) }\end{array}$ & (1) Redcedar & Moderate (2) \\
\hline 3 & (3) ${ }^{\text {Loam }}$ & (1) Redcedar & Low \\
\hline 4 & (1) $\begin{array}{l}\text { Mine spoil } \\
\end{array}$ & (2) $\begin{array}{r}\text { Maple } \\
\end{array}$ & Moderate (2) \\
\hline 5 & $\begin{array}{l}\text { Chernozem } \\
\text { (2) }\end{array}$ & (2) ${ }^{2}$ Maple & Low \\
\hline 6 & (3) ${ }^{\text {Loam }}$ & (2) ${ }^{2}$ Maple & High (1) \\
\hline
\end{tabular}




\begin{tabular}{|c|c|c|c|}
\hline 7 & \multicolumn{2}{|c|}{ Mine spoil } & \multicolumn{2}{|c|}{ Robinia } & Low (3) \\
\hline 8 & \multicolumn{2}{|c|}{ (3) Chernozem } & \multicolumn{2}{|c|}{ Robinia } & High (1) \\
\hline 9 & \multicolumn{2}{|c|}{ Loam } & \multicolumn{2}{|c|}{ Robinia } & Moderate (2) \\
\hline
\end{tabular}

When studying the reaction of soil animals to the habitation conditions, physical- and chemical characteristics of the substrates and litters are very important. Therefore we considered the basic properties.

The mine spoil is of grey colour; when wetting, it gets the properties of structureless patching material containing small insertions of coal and occasionally pyrite. In the granulometric composition it relates to heavy silty-pulverescent loams. The absence of bivalent cations is characteristic for the mine spoil. In the physical, chemical, water-, air- and mechanical properties the mine spoil is not suitable for the growth of plants (Travleev et al., 1988, 2005; Masyuk, 1988).

The samples of ordinary chernozem are presented by moderate and heavy silty-pulverescent loams with the saturation base up to $97 \%$. In the composition of the soil-absorbing complex prevails $\mathrm{Ca}^{2+}$ (up to $90 \%$ ) and $\mathrm{Mg}^{2+}$ (up to $10 \%$ ). The shares of $\mathrm{Na}^{+}$and $\mathrm{K}^{+}$are low. The concentration of humus is up to $4.0 \%$.

In respect of the contents of physical clay (up to $33 \%$ ), the loess loam of pale-yellow coloration refers to light loams, and as to the prevailing fraction, this refers to those of silty-sandy (Masyuk, 1989). The amount of humus from trace values is up to $0.9 \%$. The effervescence from $10 \%$ of $\mathrm{HCl}$ is absent; that testifies to the absence of carbonates of calcium and magnesium.

\section{RESULTS AND DISCUSSION}

The results of measurements of the animal biomass of are given in Table 2. In the right-hand column are the indicated average values of a biomass increase of the animals which reflect the difference between the biomass before and after the experiment.

Results of experiment shows changes in animal biomass with significance level $\alpha=0.0004$. The statistical assessment of permanent effects made with the use of dispersive analysis has shown that they influence significantly the change in biomass of the representatives of Lumbricidae. So, the significance level of the substrate's influence was 0.022 , that of the litter 0.008 , and that of the humidification 0.017 .

Table 2.

Conditions of planning and a biomass increase $(\Delta)$ of earthworms $(n=10$ specimen/ 1 container $)$ during one month

\begin{tabular}{|c|c|c|c|c|c|c|c|c|}
\hline \multirow{2}{*}{$\begin{array}{c}\text { Test } \\
\text { number }\end{array}$} & \multicolumn{9}{|c|}{ Replication 1 } & \multicolumn{4}{c|}{ Replication 2 } \\
\cline { 2 - 9 } & Substrate & Litter & Watering & $\Delta \cdot 10^{-3}, \mathrm{~kg}$ & Substrate & Litter & Watering & $\Delta \cdot 10^{-3}, \mathrm{~kg}$ \\
\hline 1 & 1 & 1 & 1 & 1.38 & 1 & 1 & 1 & 1.25 \\
\hline 2 & 2 & 1 & 2 & 2.42 & 2 & 1 & 2 & 3.22 \\
\hline 3 & 3 & 1 & 3 & 0.61 & 3 & 1 & 3 & 1.98 \\
\hline 4 & 1 & 2 & 2 & 4.17 & 1 & 2 & 2 & 4.91 \\
\hline 5 & 2 & 2 & 3 & 4.36 & 2 & 2 & 3 & 4.26 \\
\hline 6 & 3 & 2 & 1 & 5.84 & 3 & 2 & 1 & 5.48 \\
\hline 7 & 1 & 3 & 3 & -0.77 & 1 & 3 & 3 & 0.71 \\
\hline 8 & 2 & 3 & 1 & 7.48 & 2 & 3 & & 3.83 \\
\hline 9 & 3 & 3 & 2 & 3.29 & 3 & 3 & 2 & 7.02 \\
\hline
\end{tabular}

The analysis of received data shows that juniper litter, weak humidification and mine spoil promote the least the biomass increase of earthworms. The greatest changes in biomass are characteristic of treatments with a maple litter, low humidification and chernozem (Table 3). The application of a layer of chernozem or loam on the mine spoil can compensate partly the negative influence on living organisms. Thus the chernozem shows the most positive ecological effect on such an important structural parameter as biomass of the soil animals. The biomass of earthworms with the use of false acacia tree waste is a little bit less than with the application of maple tree waste. However, the effect of these two tree wastes exceeds significantly the effect of juniper tree waste. Therefore, it is expedient to use maple and false acacia plantings at remediation. Thus such forest belts will act as reserves for different representatives of soil saprophages and other animals participating in the ecological stabilization of the artificial ecosystems. 
Average values of biomass increase for earthworms depending on the gradation of factors $\left(\mathrm{kg} \cdot 10^{-3}\right)$

\begin{tabular}{|c|c|c|}
\hline Level of factor & $\begin{array}{c}\text { Number } \\
\text { of tests }\end{array}$ & $\begin{array}{c}\text { Arithmetic } \\
\text { average }\end{array}$ \\
\hline \multicolumn{3}{|c|}{ Litter } \\
\hline Red cedar & 6 & 1.810 \\
\hline Maple & 6 & 4.837 \\
\hline Robinia & 6 & 3.593 \\
\hline Humidification \\
\hline High & 6 & 4.210 \\
\hline Moderate & 6 & 4.172 \\
\hline Low Substrate \\
\hline \multicolumn{2}{|c|}{6} & 1.858 \\
\hline Mine spoil & 6 & 1.942 \\
\hline Chernozem & 6 & 4.262 \\
\hline Loam & 6 & 4.037 \\
\hline
\end{tabular}

It is known that earthworms require the sufficient humidification. The performed researches have shown that the biggest values of worm biomass are observed with the moderate and high humidification (from 30 up to 40 $\mathrm{mm} / \mathrm{month}$ ). Below this level the biomass of earthworms decreases dramatically several times. Forest plantings retain moisture in soil and serve as an additional source for moisture accumulation that favours to the normal development of soil biota and grass vegetation. Due to this water content, the physical and chemical properties of soil are improved.

As at both the agricultural and other types of re-cultivation the protective forest belts are created serving as concentrators of the biodiversity under the severe climatic conditions of steppe, it was necessary to find out what tree waste of what kind of wood species is optimal for the formation and existence of the communities of soil saprophages. Mostly, under the steppe conditions such wood species, as eastern red cedar, Bosnian maple and false acacia are used for remediation. Therefore, the tree waste of these tree species was used in the experiment.

The results of paired comparison (according to the Duncan multiple rank test) of all the processing methods are given in Table 4. There in specified contrasts the sign "<" shows that the average value of biomass of earthworms at the first method of processing in the experiment is less than the average value of biomass at that of second.

Table 4.

Pair comparisons of processing methods

\begin{tabular}{|c|c|c|}
\hline \multicolumn{2}{|c|}{ Contrast } & Statistical distinctions of effects \\
\hline \multicolumn{3}{|c|}{ Substrate } \\
\hline First method of processing & Second method of processing & \\
\hline Mine spoil < & Chernozem & $\leq 0.05$ \\
\hline Mine spoil $<$ & Loam & $\leq 0.05$ \\
\hline Chernozem $<$ & Loam & None \\
\hline \multicolumn{3}{|c|}{ Litter } \\
\hline First method of processing & Second method of processing & \\
\hline Red cedar $<$ & Maple & $\leq 0.05$ \\
\hline Red cedar $<$ & Robinia & $\leq 0.05$ \\
\hline Maple < $<$ & Robinia & None \\
\hline \multicolumn{3}{|c|}{ Humidification } \\
\hline First method of processing & Second method of processing & \\
\hline High $<$ & Moderate & None \\
\hline Low $<$ & Moderate & $\leq 0.05$ \\
\hline Low & Moderate & $\leq 0.05$ \\
\hline
\end{tabular}

It has been found out that there is a statistically significant difference between the average biomass of earthworms in following pairs of processing methods: mine spoil - loam; mine spoil - chernozem; juniper litter - maple litter; red cedar litter - acacia litter. Smaller values of biomass are characteristic of them at the first specified method of processing in the compared pair. 


\section{CONCLUSIONS}

Soil biota has active reaction on changes of habitat condition due to changes of structural-functional characteristics (number, biomass etc.). As a result of the performed experiments it has been proved that the change in biomass of earthworms (Lumbricidae) depends upon the species of substrate used as the environment, and also upon leaf litter of wood species applied onto the substrate, and the humidification level. The processing of the experiment data has allowed showing a statistically proved decrease in biomass of the representative of Lumbricidae at the presence of mine spoil, red cedar litter and insufficient humidification. On the contrary, the studied characteristic increases, if such substrates as loam and chernozem are used, maple and false acacia litters are brought in, and also moderate humidification is carried out.

The presence of artificial forest belts on the re-cultivated territory influences positive effect on the condition of soil biota. They are reservations for the habitation, and the wood litter, especially the leaf of trees is the important source for the nutrition. Wood litter of red cedar juniper is the least suitable for the nutrition of earthworms. Leaf tree wastes of Bosnia maple and false acacia are a good food reserve for the nutrition of earthworms. Exactly these wood species are recommended for the creation of artificial forest belts on the territories of agricultural remediation in condition of Steppe zone of Ukraine.

\section{REFERENCES}

Atlavinite, O. P.: 1982. Ecology of Earthworms and Their Influence on the Fertility of Soil in the Lithuanian SSR. Vilnius, Lithuania. 201.

Giliarov, M. S. - Striganova, B. R.: 1978. The Role of Soil Invertebrates in the Decomposition of Vegetational Residues and the Cycling of Matter. Paper: Results of Science, Zoology of Invertebrates (Edaphic Zoology). Moscow, Russia: 8-69.

Gritsan, Y. I.: 2000. The Environmental Principles of Transformed Influence of Sylva on the Steppe Environment. Dnepropetrovsk: Dnepropetrovsk State University. 300.

Ivantsiv, V. V. - Buslenko, L. V. - Shchepka, L. V.: 2002. The Influence of Ground Annelid Worms on Restructuring of Condensed Soil of the Western Regions of Ukraine. Iss. 6: 87-90.

Kharytonov, M. M. - Zhilenko, M. I.: 2006. The Assessment of Environmental Safety for the Variants of Agricultural Re-cultivation at Western Donbass. Bulletin of Kharkiv Agrarian University. Kyiv. Ukraine. Iss. 6: 210-212.

Kondratyuk, E. N.: 1980. Industrial Botany. Kyiv. Ukraine. 254.

Kulbachko, Y. L. - Didur, O. A. - Loza, I. M.: 2008. The Assessment's of Influence for the representatives of Begiminate-Legged Multilegs (Diplopoda) on the Emission of Carbon Dioxide with Modelling of Mixed-Soils When Solving the Problems of Re-cultivation of the Damaged Soils. The Problems of Ecology and the Protection of Nature in the Anthropogenic Region. Donetsk. Ukraine. Iss. 7: 93-99.

Loza I. M. - Nazarenko, N. N.: 2006. The Formation of New Wetlands in Subsidence Hollows of Western Donbass, Ukraine. Paper: The Environmental Role of Wetlands in Headwaters (eds. J. Krecek and M. Haigh), Springer: NATO Science Series. Netherlands. 135-141.

Masyuk, A. N.: 1988. The Productivity of Wood Cultures in the Re-cultivated Soil of Western Donbass. Paper: Monitoring Researches of Wood Ecosystems of the Steppe Zone, Their Preservation and Rational Use. Dnepropetrovsk. Ukraine. 109-117.

Masyuk, A. N.: 1989. False acacia on the Re-cultivated Soil of Western Donbass. Paper: Biogeocenological Researches of the Woods in Technogenic Landscapes of the Ukraine Steppe. Dnepropetrovsk. Ukraine. 139-151.

Nalymov, V. V.: 1971. The Theory of an Experiment. Moscow. Russia. 207.

Polupan, M. I. - Solovyov, V. B. - Velichko, V. A.: 2005. The Classification of Ukraine's Soils. Edited by M. I. Polupan. Kyiv: Rural Science. 300.

The Soils of Dnepropetrovsk Region and the Ways of Their Rational Use: 1966. Dnepropetrovsk. Ukraine. 104.

Tomashevskiy, V. M.: 2005. The Modeling Systems. Kyiv. Ukraine. 352.

Travleev, A. P. - Belova, N. A. - Zverkovskiy, V. M.: 2005. The Theory of Forest Re-cultivation and Damaged Soil in Western Donbass in Dnepropetrovsk Region. Paper: Gruntoznavstvo. Iss. 16, \# 1-2: 19-29.

Travleev, A. P. - Ovchinnikov, V. A. - Zverkovskiy, V. N.: 1988. The Biogeocenotic Cover of Western Donbass, its Technogenic Dynamics and Optimization. An Educational Book. Dnepropetrovsk. Ukraine. 98.

Vsevolodova-Perel, T. S.: 1997. The Earthworms of Russia Fauna. The Cadastre and Determinant. Moscow, Russia. 103.

World Reference Base for Soil Resources: 1994. Draft. ISSS/ISRIC // FAO. Wageningen / Rome. 161.

Zonn, S. V. - Travleev A. P.: 1989. Geographical and Genetic Aspects of Pedogenesis, Evolution and Preservation of Soil. Kyiv. Ukraine. 216.

Zrazhevskiy, A. I.: 1957. Earthworms as the Factor of Fertility of Wood Soils. Kyiv: Publishing House of Academy of Science of Ukraine. 271. 